\title{
A Novel Membrane Sensor for Histamine H1-Receptor Antagonist "Fexofenadine"
}

\author{
M. N. Abbas, ${ }^{* \dagger}$ A. A. Abdel Fattah, ${ }^{* *}$ and E. Zahran* \\ *Microanal. Lab., Appl. Org. Chem. Dept., National Research Centre, Dokki, Cairo, Egypt \\ **Chem. Dept. Fac. Sci., Benha Branch, Zagazig University, Benha, Egypt
}

\begin{abstract}
The construction and general performance of thirteen new polymeric membrane sensors for the determination of fexofenadine hydrochloride based on its ion exchange with reineckate, tetraphenylborate and tetraiodomercurate have been studied. The effects of membrane composition, type of plasticizer, $\mathrm{pH}$ value of sample solution and concentration of the analyte in the sensor internal solution have been thoroughly investigated. The novel sensor based on reineckate exchanger shows a stable, potentiometric response for fexofenadine in the concentration range of $1 \times 10^{-2}-2.5 \times 10^{-6} \mathrm{M}$ at $25^{\circ} \mathrm{C}$ that is independent of $\mathrm{pH}$ in the range of $2.0-4.5$. The sensor possesses a Nernstian cationic slope of $62.3 \pm 0.7$ $\mathrm{mV} /$ concentration decade and a lower detection limit of $1.3 \times 10^{-6} \mathrm{M}$ with a fast response time of $20-40 \mathrm{~s}$. Selectivity coefficients for a number of interfering ions and excipients relative to fexofenadine were investigated. There is negligible interference from almost all studied cations, anions, and pharmaceutical excipients, however, citrizine that has a structure homologous to that of fexofenadine was found to interfere. The determination of fexofenadine in aqueous solution shows an average recovery of $99.83 \%$ with a mean relative standard deviation (RSD) of $0.5 \%$. Direct potentiometric determination of fexofenadine in tablets gave results that compare favorably with those obtained by standard spectrophotometric methods. Potentiometric titration of fexofenadine with phosphomolybdic acid as a titrant has been monitored with the proposed sensor as an end point indicator electrode.
\end{abstract}

(Received November 25, 2003; Accepted April 6, 2004)

\section{Introduction}

Antihistamines are H1-receptor antagonists widely used in human and veterinary medicine to provide symptomatic relief of allergic signs caused by histamine release, including pruritus and anaphylactic reactions. They are also commonly used as sedatives and antiemetics. ${ }^{1}$ Antihistamines can be divided into first-and second-generation (also called non-sedating) agents. First-generation antihistamines are small lipophilic molecules, so they may cause adverse effects because of their cholinergic activity and their ability to cross the blood-brain barrier. Second-generation antihistamines are more lipophobic than first-generation antihistamines and are thought to lack central nervous system (CNS) and cholinergic effects when given at therapeutic doses. ${ }^{2}$ Fexofenadine hydrochloride, the active ingredient of Allegra and Telfast, is a second-generation histamine H1-receptor antagonist with the chemical name $( \pm)-4$ [1-hydroxy-4-[4-(hydroxyldiphenylmethyl)-1-piperidinyl]butyl]- $\alpha, \alpha$-dimethylbenzeneacetic acid hydrochloride, and has the chemical structure shown in Fig. 1(a). It is the active metabolite of terfenadine, it does not cross the blood-brain barrier and appears to display some anti-inflammatory properties. The literature reports that no evidence of toxicosis was observed in $\operatorname{dog} s$ and cats receiving relatively high oral fexofenadine doses. ${ }^{3}$ For all mentioned properties, fexofenadine is widely and successfully used as anti-allergic agent in many parts of the world. The determination of fexofenadine has been

$\doteqdot$ To whom correspondence should be addressed.

E-mail: mnabbas@menanet.net described using HPLC, ${ }^{4-6}$ spectrophotometry ${ }^{7,8}$ and fluorimetry. ${ }^{8}$ No electrochemical method has been yet reported in the literature for the determination of fexofenadine; therefore it is worth developing a simple potentiometric sensor for its fast determination. ISE's are known to offer an excellent low cost tool for the selective, sensitive and rapid determination of a vast variety of analytes in different fields of application, ${ }^{9-13}$ including pharmaceutical analysis. ${ }^{9}, 11,12$ The present study aims to develop a potentiometric sensor for the selective, accurate and fast determination of fexofenadine in its pharmaceutical preparations.

\section{Experimental}

\section{Reagent and materials}

All chemicals used were of analytical reagent grade unless otherwise stated and doubly distilled water was used throughout. Fexofenadine was kindly supplied by Hockest, Marion, Roussel, Alexandria, Egypt and Telfast was kindly supplied by Avintes Pharma, Cairo, Egypt. A stock solution of $0.01 \mathrm{M}$ was prepared by dissolving $0.53813 \mathrm{~g}$ of fexofenadine hydrochloride in $100 \mathrm{ml}$ of phthalate buffer of $\mathrm{pH} \mathrm{3.5}$. The working standards of $10^{-3}, 10^{-4}$, and $10^{-5} \mathrm{M}$ concentration were prepared by proper dilution of the stock solution. Phthalate buffer of $\mathrm{pH} 3.5$ was prepared by adding $50 \mathrm{ml}$ of $0.2 \mathrm{M}$ potassium phthalate solution to $15.7 \mathrm{ml}$ of $0.1 \mathrm{M} \mathrm{HCl}$; the mixture was brought up to $200 \mathrm{ml}$ with water. Dioctyl phthalate (DOP), dibutyl phthalate (DBP), dibutyl sebacate (DBS), onitrophenyl octyl ether (2-NPOE), and tetrahydrofuran (THF) were purchased from Aldrich, sodium tetraphenyl borate and 
ammonium reineckate were purchased from Reidel de Haen. Polyvinyl chloride (PVC) (high molecular weight) fine powder was purchased from Fluka, Switzerland.

\section{Apparatus}

All potentiometric measurements were made at $25 \pm 1{ }^{\circ} \mathrm{C}$ unless otherwise stated using a Metrohm $\mathrm{pH} /$ ion meter (Model 692). A combined glass $\mathrm{pH}$ electrode (Metrohm 6.0202.100) was used for all $\mathrm{pH}$ measurements and a Metrohm double junction $\mathrm{Ag} / \mathrm{AgCl}$ reference electrode (Model 6.0726.100) containing $3 \mathrm{M}$ potassium chloride in outer and inner tubes was used.

\section{Preparation of ion-pairs}

The fexofenadine-reineckate ion-pair (Fexo-R) was prepared by mixing $100 \mathrm{ml}$ of $10^{-2} \mathrm{M}$ fexofenadine hydrochloride solution with $100 \mathrm{ml}$ of $10^{-2} \mathrm{M}$ ammonium reineckate. The formed precipitate was filtered off, thoroughly washed with distilled water and allowed to air dry. The fexofenadinetetraphenylborate (Fexo-TPB) and fexofenadinetetraiodomercurate (Fexo-TIM) ion-pairs were similarly prepared using proper concentrations.

\section{Preparation of the membrane}

PVC membranes containing $1.8 \%, 2.7 \%$, and $3.7 \%$ concentrations (w/w) of Fexo-R, Fexo-TPB, and Fexo-TIM ionpairs were prepared ${ }^{9}$ by dissolving $10 \mathrm{mg}, 15 \mathrm{mg}$, and $20 \mathrm{mg}$ respectively of the named ion-pairs in $350 \mu \mathrm{l}$ of DOP as a plasticizer. The ion-pair solution was then well mixed with 190 $\mathrm{mg}$ of PVC in a 5-cm Petri dish. The mixture was then completely dissolved in $5 \mathrm{ml} \mathrm{THF}$, and allowed to evaporate over night while the sensing membrane slowly formed. Three other electrodes of fexofenadine-reineckate ion-pair with $2.7 \%$ concentration were prepared using DBP, DBS, and NPOE plasticizers.

\section{Construction of the electrode}

A disc of $0.8 \mathrm{~cm}$ diameter was cut out from the master membrane by a cork borer, and stacked onto one end of a poly ethylene tube using a solution of PVC in THF; ${ }^{14,15}$ then the tube was fitted onto a locally-made glass shaped electrode. The electrode was always filed with a mixture of equal volumes of $10^{-2} \mathrm{M}$ fexofenadine hydrochloride and $10^{-2} \mathrm{M} \mathrm{KCl}$ solutions, except for sensor $(\mathrm{G})$, where $10^{-3} \mathrm{M}$ fexofenadine hydrochloride was used.

\section{Calibration of the sensor}

The sensor was calibrated by immersion in conjugation with the reference electrode in a $50 \mathrm{ml}$ tall beaker containing $10 \mathrm{ml}$ of fexofenadine solution of concentration ranging from $10^{-4}$ to $10^{-2} \mathrm{M}$ in phthalate buffer of $\mathrm{pH} 3.5$ with continuous stirring. The potential was recorded after stabilization to $\pm 0.2 \mathrm{mV}$. A calibration graph was then constructed by plotting the recorded potential versus $-\log$ [fexofenadine]. The sensor was soaked in $10^{-2} \mathrm{M}$ fexofenadine solution for $2 \mathrm{~h}$ before its first use and stored in the same solution.

Determination of fexofenadine hydrochloride in "Telfast" tablets Ten tablets of Telfast, 60, 120 or $180 \mathrm{mg}$ were pulverized and carefully homogenized. Then a weight that is equivalent to the average weight of one tablet was dissolved in water by shaking for 5 min with a mechanical shaker. Filtration, the filtrate was made up to $100 \mathrm{ml}$ and $1 \mathrm{ml}$ of that solution was delivered into a measuring beaker containing $9 \mathrm{ml}$ of phthalate buffer solution of $\mathrm{pH}$ 3.5. The potential was then measured using the proposed (a)

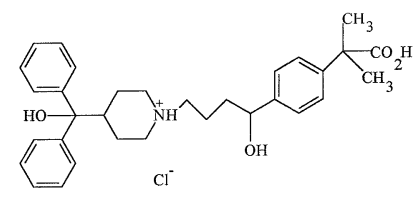

(b)

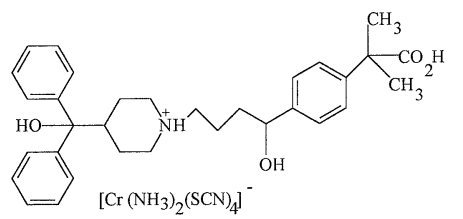

(c)

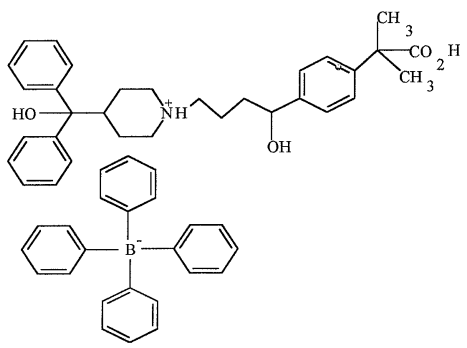

(d)

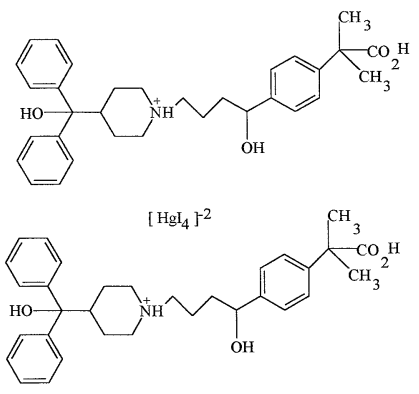

Fig. 1 The molecular structural formula of (a) fexofenadine hydrochloride, (b) fexofenadine-reineckate, (c) fexofenadinetetraphenylborate and (d) fexofenadine-tetraiodomercurate.

electrode for three replicates. The concentration of fexofenadine was obtained by applying the following electrode equation:

$$
E=331.2+62.3 \times \log [\text { fexofenadine }]
$$

Eosin spectrophotometric method for determination of fexofenadine

A $100-\mu 1$ volume of the sample solution was transferred using a micropipette into a $10 \mathrm{ml}$ volumetric flask, then $0.5 \mathrm{ml}$ of $(0.5$ $\mathrm{g} \mathrm{w} / \mathrm{v} \%$ ) methylcellulose solution in water was added followed by $1.5 \mathrm{ml}$ of eosin solution and $1 \mathrm{ml}$ of Melivaine's citric acid phosphate buffer of $\mathrm{pH}$ 3.0. After standing for $10 \mathrm{~min}$ at room temperature the mixture was diluted to volume with water. The absorbance was measured at $541 \mathrm{~nm}^{7}$

\section{Results and Discussion}

Fexofenadine hydrochloride is a white to off-white crystalline powder that is freely soluble in methanol and ethanol, slightly soluble in chloroform and water, and insoluble in hexane. It exists as a zwitterion in aqueous media at physiological $\mathrm{pH}$, and was found to give insoluble precipitates with sodium reineckate, sodium tetraphenylborate and potassium tetraiodomercurate. The composition of the resulting ion-pairs show molar 
Table 1 Percentage composition of the different membranes of fexofenadine sensors

\begin{tabular}{ccllll}
\hline Membrane & PVC, \% & \multicolumn{2}{c}{ Ion-pair, \% } & \multicolumn{2}{c}{ Plasticizer, \% } \\
\hline A & 35.0 & Fexo-R, $\quad 1.8$ & DOP, & 63.0 \\
B & 34.6 & Fexo-R, 2.7 & DOP, & 62.5 \\
C & 34.3 & Fexo-R, $\quad 3.7$ & DOP, & 62.0 \\
D & 34.6 & Fexo-R, 2.7 & DBP, & 62.5 \\
E & 34.6 & Fexo-R, 2.7 & DBS, & 62.5 \\
F & 34.6 & Fexo-R, 2.7 & 2-NPOE, 62.5 \\
G & 34.6 & Fexo-R, 2.7 & DOP & 62.5 \\
H & 35.0 & Fexo-TPB, 1.8 & DOP, & 63.0 \\
I & 34.6 & Fexo-TPB, 2.7 & DOP, & 62.5 \\
J & 34.3 & Fexo-TPB, 3.7 & DOP, & 62.0 \\
K & 35.0 & Fexo-TIM, 1.8 & DOP, & 63.0 \\
L & 34.6 & Fexo-TIM, 2.7 & DOP, & 62.5 \\
M & 34.3 & Fexo-TIM, 3.7 & DOP, & 62.0 \\
\hline
\end{tabular}

a. Internal solution $=10^{-3} \mathrm{M}$

Table 2 Characteristic performance of the different fexofenadine sensors

\begin{tabular}{ccccc}
\hline Membrane & $\begin{array}{c}\text { Slope, } \\
\text { mV/decade }\end{array}$ & $\begin{array}{c}\text { Intercept/ } \\
\mathrm{mV}\end{array}$ & $\begin{array}{c}\text { Linear range/ } \\
\mathrm{M}\end{array}$ & $\begin{array}{c}\text { LDL/ } \\
\mathrm{M}\end{array}$ \\
\hline $\mathrm{A}$ & 50.6 & 241.2 & $1 \times 10^{-4}-1 \times 10^{-2}$ & $2.6 \times 10^{-5}$ \\
$\mathrm{~B}$ & 58.1 & 264.3 & $5 \times 10^{-6}-1 \times 10^{-2}$ & $3.0 \times 10^{-6}$ \\
$\mathrm{C}$ & 43.2 & 178.8 & $3 \times 10^{-4}-1 \times 10^{-2}$ & $1.3 \times 10^{-4}$ \\
$\mathrm{D}$ & 45.5 & 205.1 & $5 \times 10^{-5}-1 \times 10^{-2}$ & $6.0 \times 10^{-6}$ \\
$\mathrm{E}$ & 53.9 & 255.0 & $5.610^{-6}-1 \times 10^{-2}$ & $2.8 \times 10^{-6}$ \\
$\mathrm{~F}$ & 30.0 & 161.2 & $1 \times 10^{-4}-1 \times 10^{-2}$ & $8.1 \times 10^{-5}$ \\
$\mathrm{G}$ & 62.3 & 331.2 & $2.5 \times 10^{-6}-1 \times 10^{-2}$ & $1.3 \times 10^{-6}$ \\
$\mathrm{H}$ & 49.5 & 243.2 & $5 \times 10^{-5}-1 \times 10^{-2}$ & $1.4 \times 10^{-5}$ \\
$\mathrm{I}$ & 51.0 & 224.4 & $1 \times 10^{-4}-1 \times 10^{-2}$ & $6.8 \times 10^{-5}$ \\
J & 53.0 & 249.4 & $1 \times 10^{-4}-1 \times 10^{-2}$ & $1.0 \times 10^{-5}$ \\
K & 28.6 & 127.9 & $5 \times 10^{-5}-1 \times 10^{-2}$ & $4.1 \times 10^{-5}$ \\
L & 44.4 & 220.6 & $1 \times 10^{-4}-1 \times 10^{-2}$ & $1.2 \times 10^{-5}$ \\
M & 45.4 & 210.8 & $1 \times 10^{-5}-1 \times 10^{-2}$ & $3.6 \times 10^{-5}$ \\
\end{tabular}

LDL: lower detection limit.

compositions of 1:1, 1:1, and 2:1 for Fexo-R, Fexo-TPB and Fexo-TIM, respectively, which was supported by elemental analysis; their structural forms are shown in Fig. 1.

\section{Potentiometric performance of the fexofenadine sensor}

Twelve plasticized PVC-based membrane ion-selective sensors incorporating Fexo-R, Fexo-TPB and Fexo-TIM ionpairs as the electro-active material in three different concentrations and four different plasticizers were prepared and their performance characteristics were evaluated according to IUPAC recommendations. ${ }^{16}$ In addition, a thirteenth sensor that has a back-fill solution with $10^{-3} \mathrm{M}$ fexofenadine has been also evaluated. Table 1 shows the percentage composition of the different fexofenadine electrodes prepared.

\section{Influence of the membrane composition}

The potentiometric sensitivity and selectivity for a given ionpair is known to depend significantly on the membrane composition. ${ }^{17-20}$ Therefore, study was performed to optimize the membrane composition using membranes containing $1.8 \%$, $2.7 \%$ and $3.7 \% \mathrm{w} / \mathrm{w}$ concentration of each of the three prepared ion-pairs (Fexo-R, Fexo-TPB and Fexo-TIM). The study was performed at $10^{-6} \mathrm{M}$ to $10^{-2} \mathrm{M}$ fexofenadine in a phthalate buffer solution of $\mathrm{pH}$ 3.5. The potentiometric characteristic
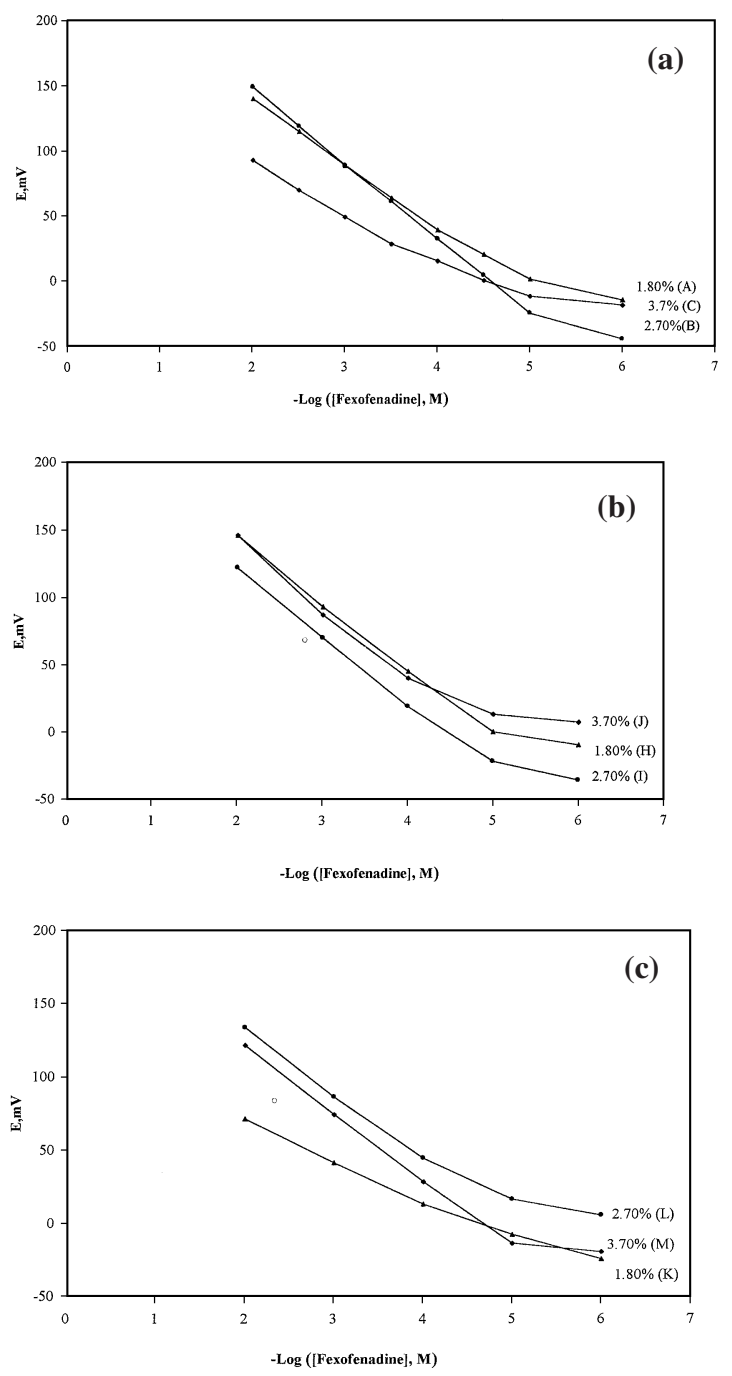

Fig. 2 The effect of ion-pair concentration on the sensors response. (a) Fexo-R sensors (A, B, C), (b) Fexo-TPB sensors (H, I, J), (c) Fexo-TIM sensors (K, L, M).

performance of thirteen newly constructed fexofenadinepolymeric sensors is given in Table 2. The data in the table show that the performance of electrodes $(\mathrm{H}, \mathrm{I}, \mathrm{J}, \mathrm{K}, \mathrm{L}$ and $\mathrm{M})$ has improved with increasing the percentage of ion-pair in the membrane. A membrane that contains $1.8 \%$ of the Fexo-R ionpair (electrode A) showed a sub-Nernstian slope of 50.6 $\mathrm{mV} /$ decade with a linear concentration range of $1 \times 10^{-4} \mathrm{M}$ to $1 \times 10^{-2} \mathrm{M}$ and a lower detection limit LDL of $2.6 \times 10^{-5} \mathrm{M}$ of the fexofenadine. However, increasing the content of ion-pair in the membrane to $2.7 \%$ (electrode B) resulted in a Nernstian slope of $58.1 \mathrm{mV} /$ decade with a linear concentration range of $5 \times 10^{-6} \mathrm{M}$ to $1 \times 10^{-2} \mathrm{M}$ and a LDL of $3 \times 10^{-6} \mathrm{M}$ of the fexofenadine. Further increase in the percentage of the ion pair to $3.7 \%$ (electrode $\mathrm{C}$ ) resulted in a decrease of the slope to 43.2 $\mathrm{mV} /$ decade with a linear concentration range of $5 \times 10^{-6} \mathrm{M}$ to $1 \times 10^{-2} \mathrm{M}$ and a LDL of $1.3 \times 10^{-4} \mathrm{M}$ of the fexofenadine. The results are shown in Fig. 2. These data can be compared with those reported in the literature; the membrane sensitivity improved by increasing the ionophore in the membrane composition up to a critical value, above which the sensitivity starts to diminish. The reason for that inflection may be attributed to saturation of the membrane or its inhomogenety. ${ }^{21,22}$ 


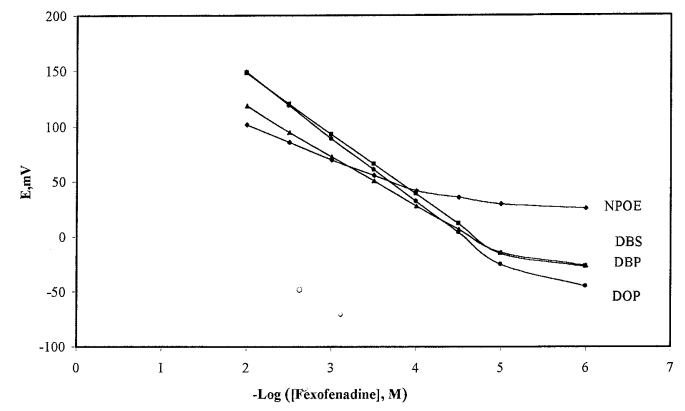

Fig. 3 The effect of different plasticizer (62.5\%) on sensor response: $\bullet$, sensor (B); $\boldsymbol{\Delta}$, sensor (D); $\mathbf{\square}$, sensor $(\mathrm{E})$; $\bullet$, sensor $(\mathrm{F})$.
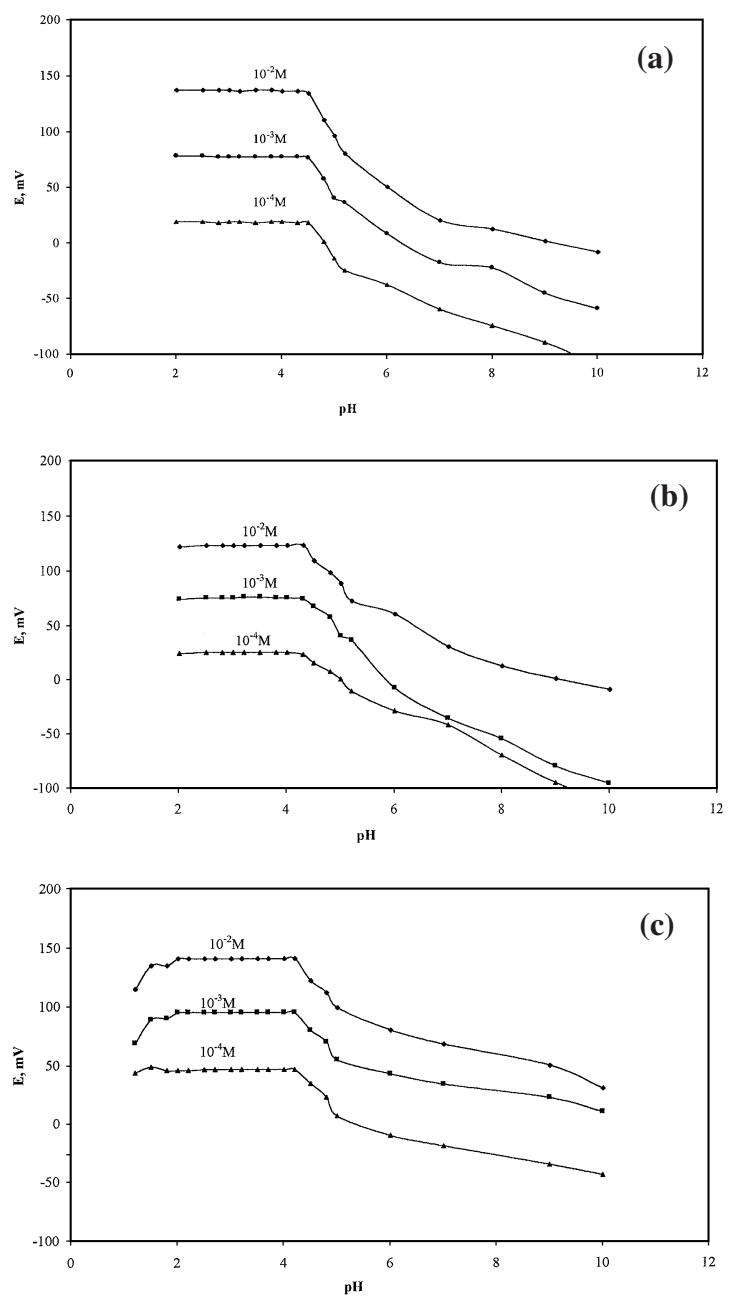

Fig. 4 The effect of $\mathrm{pH}$ on different fexofenadine sensors: (a) sensor B, (b) sensor I, and (c) sensor L.

\section{Effect of plasticizer type on the sensor response}

The plasticizer plays a vital role in the sensor performance, as it is responsible for the ion-pair solvation and distribution in the membrane, thus controlling the detection limit, ${ }^{23,24}$ affecting the selectivity and sensitivity ${ }^{25-27}$ and giving the plastic membrane the proper elasticity and strength. Also, there are many results indicating its responsibility on the mobility of the ion through the membrane. ${ }^{28}$ Therefore, the effects of four different plasticizers (DOP, DBP, DBS and 2-NPOE) on the performance

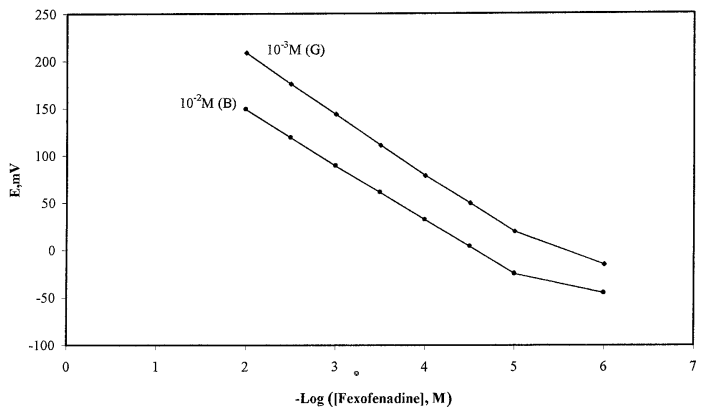

Fig. 5 The effect of concentration of fexofenadine in the internal solution on sensors (B and $G)$.

of the fexofenadine membranes (B, D, E and F) have been investigated. The effect of different plasticizers is shown in Fig. 3 , where it is clear that DOP resulted in the best sensor performance. As is clear from Table 2, sensor B with the membrane composed of $2.7 \%$ Fexo-R and plasticized with DOP showed a linear response over a concentration range from $5 \times$ $10^{-6}$ to $1 \times 10^{-2} \mathrm{M}$ with a close Nernstian slope $58.1 \mathrm{mV} /$ decade with a lower detection limit of $3 \times 10^{-6} \mathrm{M}$.

\section{Effect of $\mathrm{pH}$ on the response of fexofenadine sensor}

The effect of $\mathrm{pH}$ on the fexofenadine sensors (B, I and L) containing the Fexo-R, Fexo-TPB and Fexo-TIM ion-pair respectively, was investigated by measuring the sensor response to $1 \times 10^{-4}, 1 \times 10^{-3}$ and $1 \times 10^{-2} \mathrm{M}$ fexofenadine solutions at $\mathrm{pH}$ $1-10$, the $\mathrm{pH}$ being adjusted using $\mathrm{HCl}$ and/or $\mathrm{NaOH}$. From Fig. 4 , it is clear that the three sensors showed a stable response over the $\mathrm{pH}$ range of $2.0-4.5$, above which the sensors response started to decrease. Above $\mathrm{pH} 10$ the response became unstable. Therefore, a phthalate buffer of $\mathrm{pH} 3.5$ has been used in all further measurements.

\section{Effect of the concentration of the back-fill solution}

It is anticipated that the linear range and limit of detection could be considerably improved by varying the composition of the reference solution, as described in the literature recently. ${ }^{29,30}$ The response of the membrane electrode in relation to the variation of internal solution was investigated using the optimum membrane composition (membrane B). Three different concentrations of the analyte in back-fill solution were investigated using equal volumes of $10^{-2} \mathrm{M}$ potassium chloride with $10^{-2} \mathrm{M}$ (sensor $\mathrm{B}$ ), $10^{-3} \mathrm{M}$ (sensor $\mathrm{G}$ ) and $10^{-4} \mathrm{M}$ fexofenadine solution. The sensor containing $10^{-2} \mathrm{M}$ fexofenadine gave a linear response with a Nernstian slope of $58.1 \mathrm{mV} /$ decade and a linear concentration range from $5 \times 10^{-6}$ to $1 \times 10^{-2} \mathrm{M}$ and with a lower detection limit of $3 \times 10^{-6} \mathrm{M}$. That with $10^{-3} \mathrm{M}$ fexofenadine gave a linear response over the concentration range from $2.5 \times 10^{-6}$ to $1 \times 10^{-2} \mathrm{M}$ with a super Nernstian slope of $62.3 \mathrm{mV} /$ decade and has a lower detection limit $1.3 \times 10^{-6} \mathrm{M}$. The results are shown in Fig. 5. This result favorably agrees with that recently reported. ${ }^{13,31}$ The sensor with $10^{-4} \mathrm{M}$ fexofenadine internal solution showed unstable response.

\section{Effect of diverse ions on the fexofenadine sensor}

Potentiometric selectivity coefficients $k_{\mathrm{IJ}}^{\text {pot }}$ of the ion selective electrodes are in common use as a quantitative expression of the ability of the electrode to respond primarily to the analyte ion in the presence of interfering ion that has the same charge sign..$^{32}$ The effect of divers ions on the proposed fexofenadine electrode 


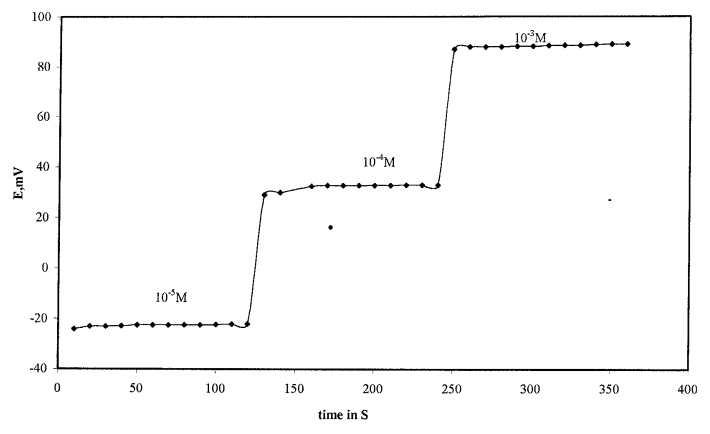

Fig. 6 The dynamic response of the fexofenadine sensor G.

was evaluated according to the recommended IUPAC 1976 separate solution method $(\mathrm{SSM})^{33}$ in which the potential response of $10^{-2} \mathrm{M}$ fexofenadine solution was measured in the first time. Then, the potential of $10^{-2} \mathrm{M}$ of the divers ion was measured in the second time and the equation:

$$
\log k_{\mathrm{I}, \mathrm{J}}^{\mathrm{pot}}=\frac{E_{\mathrm{j}}-E_{\mathrm{f}}}{62.3}-\left(\frac{1}{z-1}\right) \log [\text { fexofenadine }]
$$

was applied where: $k_{\mathrm{I}, \mathrm{J}}^{\text {pot }}$ the selectivity coefficient; $E_{\mathrm{f}}$, the potential measured of $10^{-2} \mathrm{M}$ fexofenadine solution; $E_{\mathrm{j}}$, the potential measured of $10^{-2} \mathrm{M}$ of the divers ion; $S$, the slope $(62.3 \mathrm{mV})$ of the fexofenadine electrode; $Z$, the charge number of the divers ion.

Table 3 shows the selectivity coefficients of 27 different cations. Most of the studied ions possess negligible interference to fexofenadine. Cetrizine that has a chemical structure similar to that of fexofenadine was found to interfere as expected; however, it is not likely to be present with fexofenadine in any drug formulation since they are not prescribed to patients at the same time, so they can not be present in one sample. The selectivity coefficients for glycine, loratadine, cetrizine, caffeine, and potassium ions were also evaluated using the mixed solution method (MSM); ${ }^{34}$ the potentiometric selectivity coefficient $k_{\mathrm{I}, \mathrm{J}}^{\text {pot }}$ was calculated using the following equation:

$$
k_{\mathrm{I}, \mathrm{J}}^{\mathrm{pot}}=\frac{\exp \left[\left(E_{1}-E_{2}\right) / 62.3\right]\left(a_{\mathrm{f}}-a_{\mathrm{j}}\right)}{a_{\mathrm{j}}}
$$

$E_{1}$ is the potential measured of the activity of the pure $10^{-3} \mathrm{M}$ fexofenadine solution. $E_{2}$ is the potential measured in the mixture of $10^{-3} \mathrm{M}$ fexofenadine and $5 \times 10^{-2} \mathrm{M}$ of the diverse ion. It is clear from the data shown in Table 4 that the selectivity coefficient for some monovalent ions determined using the MSM are comparable to those determined using SSM, while citrizine still possesses the highest interference measured.

\section{Response time}

The average dynamic response time of the fexofenadine sensor as determined by immersion of the electrode in $10^{-5}$, $10^{-4}, 10^{-3}$, and $10^{-2} \mathrm{M}$ solutions of fexofenadine and measuring the steady state potential within $\pm 0.5 \mathrm{mV}$ was less than $30 \mathrm{~s}$. $95 \%$ of the final response being reached within about $15 \mathrm{~s}$ (Fig. $6)$. In general, the response time is more rapid when proceeding from dilute to concentrated solutions. A 20-s response time was normal for solutions of fexofenadine concentration of more than $10^{-4} \mathrm{M}$.
Table 3 Selectivity coefficient of some cations with respect to

\begin{tabular}{|c|c|c|c|c|c|}
\hline Ion & $k \mathrm{f}_{\mathrm{j}, \mathrm{s}}^{\mathrm{pot}}$ & Ion & $k_{, J}^{\text {pot }}$ & Ion & $k_{\mathrm{f}, \mathrm{t}}^{\mathrm{ot}}$ \\
\hline L-Meth & $6.07 \times$ & $\mathrm{NH}_{4}{ }^{+}$ & 0.07 & NTI & 7.3 \\
\hline & 6.07 & $\mathrm{~K}^{+}$ & 7.35 & & \\
\hline 然 & & & & $\mathrm{Ba}^{2+}$ & 7.07 \\
\hline & & $\mathrm{Cu}^{2+}$ & $1.3 \times$ & $\mathrm{Hg}^{2+}$ & 6.3 \\
\hline Caf & & $\mathrm{Co}^{2+}$ & $6.8>$ & $\mathrm{In}^{3+}$ & 1.72 \\
\hline & $3 x$ & $\mathrm{Cd}^{2+}$ & $6.3 \times$ & $\mathrm{As}^{3+}$ & 1.47 \\
\hline ne & $7.07 \times 10^{-3}$ & $\mathrm{~Pb}^{2+}$ & $6.8 \times$ & $\mathrm{Fe}^{3+}$ & 1.86 \\
\hline etriz & 046 & $\mathrm{Ni}^{2+}$ & $7.07 \times$ & $\mathrm{Cr}^{3+}$ & $1.47 \times 10^{-2}$ \\
\hline $\mathrm{Ag}^{+}$ & $7.35 \times 10^{-4}$ & $\mathrm{Sn}^{2+}$ & $7.9 \times 10^{-3}$ & $\mathrm{Ce}^{3+}$ & $1.59 \times 10^{-2}$ \\
\hline
\end{tabular}
fexofenadine measured using SSM

Table 4 The selectivity coefficient of some cations measured using MSM

\begin{tabular}{ccrrrr}
\hline Ion & Caffiene & Glycine & Cetrizine & Loratadine & $\mathrm{K}^{+}$ \\
\hline$k_{1, \mathrm{~J}}^{\text {pot }}(\mathrm{MSM})$ & $3.3 \times 10^{-3}$ & $2.03 \times 10^{-4}$ & 0.12 & $2.1 \times 10^{-3}$ & $3.4 \times 10^{-4}$ \\
$k \mathrm{p}_{\mathrm{N}}^{\mathrm{ot}}(\mathrm{SSM})$ & $1.0 \times 10^{-3}$ & $7.6 \times 10^{-4}$ & 0.46 & $7.07 \times 10^{-3}$ & $7.35 \times 10^{-4}$ \\
\hline
\end{tabular}

Table 5 Determination of fexofenadine in pure solution using the proposed sensor

\begin{tabular}{lcc}
\hline $\begin{array}{c}\text { Added/ } \\
\mathrm{mg} \mathrm{ml}^{-1}\end{array}$ & $\begin{array}{c}\text { Potentiometry } \\
\mathrm{R} \% \pm \text { S.D. } \%\end{array}$ & $\begin{array}{c}\text { Spectrophotometry } \\
\mathrm{R} \% \pm \text { S.D.\% }\end{array}$ \\
\hline 1.6 & $99.97 \pm 0.11, F=0.76, t=0.6$ & $100.01 \pm 0.13$ \\
0.16 & $99.78 \pm 0.37, F=0.76, t=0.88$ & $99.81 \pm 0.32$ \\
0.016 & $99.75 \pm 0.28, F=0.033, t=0.32$ & $99.89 \pm 0.08$ \\
\hline
\end{tabular}

\section{Repeatability and reproducibility}

No change in the response of the sensor was observed for up to $20 \mathrm{~min}$. After $1 \mathrm{~h}$ the potential was changed only by about 3 $\mathrm{mV}$ for concentrations less than $10^{-4} \mathrm{M}$ and by $5 \mathrm{mV}$ for concentrations more than $10^{-4} \mathrm{M}$ to $10^{-2} \mathrm{M}$. The membrane sensor is useable for at least 45 days without any important change in potential. The master membrane can be used after 3 months with the same response, when stored below $4^{\circ} \mathrm{C}$.

\section{Determination of fexofenadine hydrochloride in pure solution} and in Telefast tablets

The determination of fexofenadine in its pure solution was carried out using the proposed sensor. The results were compared to those obtained using the Eison spectrophotometric method. ${ }^{7}$ Table 5 shows that the average recovery of fexofenadine from its pure solution is $99.83 \pm 0.76 \%$. The determination of fexofenadine in its pharmaceutical formulations Telfast tablets and capsules gave an average recovery of $99.23 \pm 0.76 \%$ as shown in Table 6 . The data reveal that results compare favorably with those obtained by spectrophotometry, as predicted from the $F$ and $t$ values of $F$ test and Student's $t$-test compared to their theoretical values of $F=6.39$ and $t=2.31$.

\section{Determination of fexofenadine by potentiometric titration}

In addition, the developed electrode in conjunction with an $\mathrm{Ag} / \mathrm{AgCl}$ reference electrode has been used as an end point indicator electrode for some potentiometric reactions. Titration of fexofenadine solution with a standard solution of phosphomolybdic acid as titrants, has been performed. From 
Table 6 Determination of fexofenadine in its pharmaceutical preparations using the proposed sensor

\begin{tabular}{cccc}
\hline & & & \multicolumn{2}{c}{ Found } \\
Sample & $\begin{array}{c}\text { Nominal } \\
\text { value/mg }\end{array}$ & $\begin{array}{c}\text { Potentiometry } \\
\text { R\% } \% \text { S.D.\% }\end{array}$ & $\begin{array}{c}\text { Spectrophoto- } \\
\text { metry } \\
\text { R\% } \% \pm \text { S.D.\% }\end{array}$ \\
\hline Tablet 180 & 180 & $99.7 \pm 0.5, F=0.74, t=0.89$ & $99.8 \pm 0.4$ \\
Tablet 120 & 120 & $99.7 \pm 0.8, F=0.60, t=0.35$ & $98.9 \pm 1.4$ \\
Capsule 60 & 60 & $98.3 \pm 1.0, F=0.76, t=0.39$ & $98.9 \pm 1.5$ \\
\hline
\end{tabular}

Fig. 7, it is clear that fexofenadine reacts with phosphomolybdic acid in the molar ratio $3: 1$. The titration curve was symmetrical with a very well defined potential jump of about $220 \mathrm{mV}$ indicating the high sensitivity of the sensor.

\section{Conclusion}

The three ion pairs fexofenadine-tetraphenylborate, fexofenadine-reineckate and fexofenadine-tetraiodomercurate, were prepared and used to construct thirteen polymeric membrane sensors containing three different concentrations $(1.8 \%, 2.7 \%$ and $3.7 \%)$ of each ion-pair in the membrane and plasticized with different plasticizers. It was found that the sensor containing $2.7 \%$ of fexofenadine-reineckate, plasticized with DOP, and containing a $10^{-3} \mathrm{M}$ fexofenadine concentration in the internal solution has a stable super-Nernstian slope of $62.3 \mathrm{mV}$ over the $\mathrm{pH}$ range of $2.0-4.5$, with a fast response time of $25 \mathrm{~s}$ and a lower detection limit of $1.3 \times 10^{-6} \mathrm{M}$ of fexofenadine. The sensor was used for the determination of fexofenadine in its pure solution and in drug formulation Telfast with $99.83 \pm 0.76$ and $99.23 \pm 0.76 \%$ recovery, respectively. The sensor was also used as an end point indicator for the potentiometric titration of fexofenadine.

\section{References}

1. D. C. Plumb, "Veterinary Drug Handbook", 3rd ed., 1999, Iowa State University Press, Ames.

2. M. A. Gonzalez and K. S. Estes, Int. J. Clin. Pharmacol. Ther., 1998, 36, 292.

3. "AHFS Drug Information 2000", American Society of Health-System Pharmacists, 2000, Bethesda, Md., 2 - 45.

4. T. Radhakrishnaa and G. Om Reddyb, J. Pharm. Biomed. Anal., 2002, 29, 681.

5. U. Hofmann, M. Seiler, S. Drescher, and M. Fromm, J. Chromatogr. B: Biomed. Sci. Appl., 2002, 766, 227.

6. W. Naidong, W. Z. Shou, T. Adisson, S. Maleki, and X. Jiang, Rapid Commun. Mass Spectrom., 2002, 16, 1965.

7. A. A. Gazy, H. Mahgoub, F. A. El-Yazbi, M. A. El-Sayed, and R. M. Youssef, J. Pharm. Biomed. Anal., 2002, 30, 859.

8. H. Mahgoub, A. A. Gazy, F. A. El-Yazbi, M. A. El-Sayed, and R. M. Youssef, J. Pharm. Biomed. Anal., 2003, 31, 801 .

9. M. N. Abbas, A. M. A. Homoda, and G. A. E. Mostafa, Talanta, 2000, 53, 425.

10. A. Ceresa, E. Bakker, B. Hattendorf, D. Gunther, and E. Pretsch, Anal. Chem., 2001, 73, 343.

11. M. N. Abbas, Anal. Lett., 2002, 35, 813.

12. M. N. Abbas and G. A. E. Mostafa, J. Phram. Biomed.

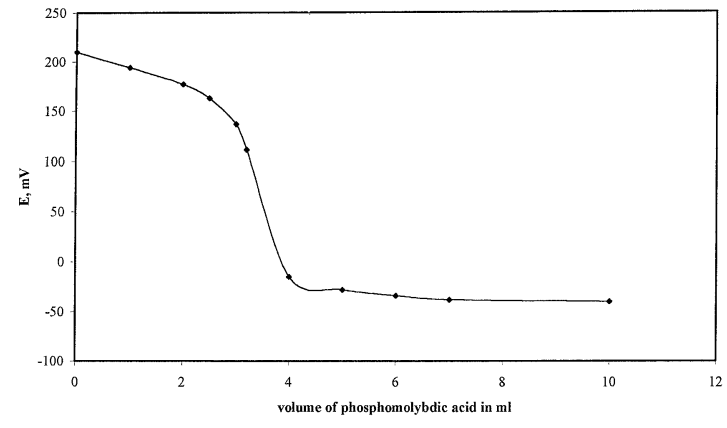

Fig. 7 Potentiometric titration of $10 \mathrm{ml}$ of $10^{-2} \mathrm{M}$ fexofenadine solution with $10 \mathrm{ml}$ of $10^{-2} \mathrm{M}$ phosphomolybdic acid using fexofenadine sensor $\mathrm{G}$.

Anal., 2003, 31, 819.

13. A. Michalaska, A. Konopka, and M. Maj-Zurawska, Anal. Chem., 2003, 75, 141.

14. T. S. Ma and S. S. Hassan, "Organic Analysis Using Ion Selective Electrodes", 1982, Vols. 1 and 2, Academic Press, London.

15. J. E. W. Davies, G. J. Moody, W. M. Price, and J. D. R. Thomas, Lab. Pract., 1973, 22, 20.

16. IUPAC Recommendation for Nomenclature of Ion Selective Electrodes, Pure Appl. Chem., 1995, 67, 507.

17. Z. Brzozka, Analyst, 1988, 113, 1803.

18. S.-R. Sheen and J.-S. Shih, Analyst, 1992, 117, 1691.

19. G. Horvia, E. Graf, K. Toth, E. Pungor, and R. P. Buck, Anal. Chem., 1986, 58, 2735.

20. K. C. Gupta and M. J. D. Arc, Talanta, 2000, 52, 1087.

21. A. Demirel, A. Dogan, E. Canel, S. Memon, M. Yilmaz, and E. Kilic, Talanta, 2004, 62, 123.

22. M. M. Ardakani, A. A. Ensafi, M. S. Niasari, and S. M. Chahooki, Anal. Chim. Acta, 2002, 462, 25.

23. E. Bakker, A. Xu, and E. Pretsch, Anal. Chim. Acta, 1994, 295, 253.

24. R. D. Armstrong and G. Harvai, Electrochim. Acta, 1990, 35,1 .

25. P. L. H. M. Cobben, R. J. M. Egberink, J. G. Bomer, P. Bergveld, and D. N. Reinhoudt, J. Electroanal. Chem., 1994, 368, 193.

26. W. E. Morf, "The Principle of Ion Selective Electrodes and of Membrane Transport", 1981, Elsevier, New York.

27. Z. Mala and J. Senkyr, Talanta, 1988, 35, 591.

28. R. E. Gyurcsanyi, E. Pergel, R. Nagy, I. Kapui, B. T. Lan, K. Toth, I. Bitter, and E. Linder, Anal. Chem., 2001, 73, 2104.

29. T. Sokalski, A. Ceresa, M. Fibbioli, T. Zwicki, E. Bakker, and E. Pretsch, Anal. Chem., 1999, 71, 1210.

30. T. Sokalski, A. Ceresa, T. Zwicki, E. Bakker, and E. Pretsch, Anal. Chem., 1999, 71, 1204.

31. A. Abbaspour, M. A. Kamyabi, A. R. Esmaeilbeig, and R. Kia, Talanta, 2002, 57, 859.

32. G. G. Guilbault, R. A. Durst, M. S. Frant, H. Freiser, E. H. Hansen, T. S. Light, E. Pungor, G. Rechnitz, M. N. Rice, T. J. Rohm, W. Simon, and D. R. Thomas, Pure Appl. Chem., 1976, 48, 127.

33. K. Umezawa and Y. Umezawa (ed.), "CRC Handbook of Ion Selective Electrodes: Selectivity Coefficients", 1990, CRC Press, Boca Raton.

34. K. Srinivassan and G. A. Rechnitz, Anal. Chem., 1969, 41, 1203. 